\title{
A METODOLOGIA EM UMA PESQUISA
}

\author{
${ }^{1}$ Andrea Orengo Maciel, ${ }^{2}$ Henrique John Pereira Neves \\ ${ }^{1}$ Universidade Federal de Pernambuco, discente especial do Curso de Mestrado em Direitos \\ Humanos do Programa de Pós Graduação em Direitos Humanos \\ ${ }^{2}$ Centro Universitário Joaquim Nabuco de Paulista-PE, docente dos Cursos de Administração, \\ Contabilidade, Direito e Tecnólogos em Logística e Recursos Humanos \\ 1e-mail: decaorengo2@gmail.com
2e-mail: henriquejohn@yahoo.com.br
}

\begin{abstract}
RESUMO - Toda pesquisa científica, tanto em cursos de graduação quanto em cursos de pós graduação, deve ser estruturada, o que ocorre com a elaboração de um projeto de pesquisa, o qual servirá de base, guia, orientação, para o desenvolvimento, execução da pesquisa. Após a realização da pesquisa, os resultados obtidos durante a execução da pesquisa devem ser apresentados em um trabalho, documento, podendo ser um artigo científico, monografia, dissertação ou tese de doutorado, por exemplo. Tanto no projeto de pesquisa, quanto no trabalho de conclusão da pesquisa, a metodologia adotada para a realização da pesquisa deve ser apresentada, para que o leitor compreenda como a pesquisa foi executada. A metodologia adotada na pesquisa deve ser escrita de forma detalhada para que o pesquisador consiga executar as etapas da pesquisa de forma a alcançar os objetivos pretendidos, demonstrando a viabilidade da pesquisa, mostrando por exemplo o tipo de pesquisa, forma de coleta de dados, tratamento e interpretação de dados, se a pesquisa é quantitativa, qualitativa, transversal, longitudinal, se a pesquisa envolve direta ou indiretamente seres humanos, se os dados são primários ou secundários, critérios de inclusão e exclusão, se a pesquisa é de revisão de literatura, dentre outras informações.
\end{abstract}

Palavras-Chave: Metodologia; Pesquisa; Tipos de Pesquisa; Dados; Coleta de Dados.

\section{INTRODUÇÃO}

Quando um pesquisador decide realizar uma pesquisa, qualquer que seja o nível da mesma, graduação ou pós graduação, lato sensu ou stricto sensu, bem como qualquer que seja a área do conhecimento, seja humana, exatas ou saúde, o mesmo deve apresentar a metodologia adotada para a realização da mesma.

A metodologia utilizada na pesquisa tem papel fundamental para o pesquisador e para o leitor do projeto de pesquisa ou do trabalho de conclusão da pesquisa, vai servir para guiar, orientar como o pesquisador deve executar seu estudo, sua pesquisa, de forma a facilitar sua implementação. Subsidiariamente vai mostrar se a pesquisa da forma como foi estruturada e organizada, se ela é viável ou não, ou seja, se ela é possível ou não de ser executada da forma como a metodologia foi apresentada.

Em um estudo, uma pesquisa, na metodologia é importante mostrar dentre outras coisas, por exemplo, o local de realização da pesquisa, se a pesquisa vai ser quantitativa, qualitativa ou quanti-qualitativa, quais dados serão utilizados na pesquisa, como estes dados serão coletados, da mesma forma como estes dados serão organizados para serem analisados, importante também se os dados serão primários ou secundários, como ocorre a distribuição dos dados ao longo do tempo em que os eventos de interesse 
ocorrem, se a pesquisa envolve ou não seres humanos, direta ou indiretamente.

Este trabalho teve por objetivo apresentar algumas das classificações possíveis que podem ser feitas na metodologia adotadas em um trabalho de pesquisa científica por parte do pesquisador, apresentado estas classificações tanto em um projeto de pesquisa, quanto em um trabalho de conclusão de pesquisa, seja um artigo científico, monografia, dissertação de mestrado, tese de doutorado, dentre outros trabalhos.

\section{CLASSIFICAÇÕES DA METODOLOGIA EM UMA PESQUISA}

Existem diversas classificações utilizadas, desenvolvidas pelos mais diversos estudiosos na área da metodologia científica, dentre as mais comumente utilizadas, existem as seguintes:

- Quanto à finalidade;

- Quanto à natureza;

- Quanto à abordagem;

- Quanto aos objetivos;

- Quanto aos procedimentos;

- Quanto ao tempo;

- Quanto ao local;

- Quanto aos critérios de escolha de dados;

- Quanto ao tratamento de dados e

- Quanto ao estudo com seres humanos.

\subsection{Quanto à Finalidade}

No que se refere à finalidade da pesquisa, de acordo com Gil (2008), pode ser:

a) Pura ou básica: em que está preocupada apenas na geração, criação de novos conhecimentos para colaborar com o desenvolvimento da ciência, sem estar preocupado com a aplicação do conhecimento construído.

b) Aplicada: pesquisa que tem a preocupação em desenvolver um conhecimento prático, aplicável a uma situação clara, concreta, real. O conhecimento construído deve ser voltado para uma aplicação prática.

\subsection{Quanto à Natureza}

No que tange à natureza da pesquisa, Silva (2004) classifica como:

a) Observacional: Neste tipo de estudo, o investigador atua meramente como expectador de fenômenos ou fatos, sem, no entanto, realizar qualquer intervenção que possa interferir no curso natural e/ou no desfecho dos mesmos, embora possa, neste meio tempo, realizar medições, análises e outros procedimentos para coleta de dados.

b) Experimental: É toda pesquisa que envolve algum tipo de experimento. Neste tipo de estudo, o pesquisador participa ativamente na condução do fenômeno, processo ou do fato avaliado, isto é, ele atua na causa, modificandoa, e avalia as mudanças no desfecho. Neste tipo de pesquisa, o investigador seleciona as variáveis que serão estudadas, define a forma de controle sobre elas e observa os efeitos sobre o objeto de estudo, em condições préestabelecida.

\subsection{Quanto à Abordagem}

Nesta classificação, de acordo com Oliveira (2011), a pesquisa pode ser tipificada como: 
a) Qualitativa: trabalha os dados buscando seu significado, tendo como base a percepção do fenômeno dentro do seu contexto. O uso da descrição qualitativa procura captar não só a aparência do fenômeno como também suas essências, procurando explicar sua origem, relações e mudanças, e tentando intuir as consequências.

b) Quantitativa: é caracterizada pelo emprego da quantificação, tanto nas modalidades de coleta de informações quanto no tratamento delas por meio de técnicas estatísticas, procura quantificar os dados e aplica alguma forma da análise estatística.

c) Quanti-Qualitativa: quando há o emprego de um estudo tanto quantitativo quanto qualitativo, objetivando utilizar as duas formas para que uma explique os dados e estudos apresentados pela outra forma.

\subsection{Quanto aos Objetivos}

Gil (2008) classifica a pesquisa quanto aos objetivos em:

a) Exploratória: objetiva facilitar familiaridade do pesquisador com o problema objeto da pesquisa, para permitir a construção de hipóteses ou tornar a questão mais clara. Os exemplos mais conhecidos de pesquisas exploratórias são as pesquisas bibliográficas e os estudos de caso.

b) Descritiva: busca a descrição de características de populações ou fenômenos e de correlação entre variáveis. São apropriadas a levantamentos.

c) Explicativa: tem uso mais restrito. Emprega o método experimental de pesquisa, é dotada de complexidade, servindo para identificar atributos ou fatores que determinam a ocorrência de fenômenos.

\subsection{Quanto aos Procedimentos}

Nesta classificação, que alguns autores chamam de delineamento da pesquisa, existem alguns tipos, contudo Lakatos e Marconi (2003) e Gil (2008) apresentam as seguintes como mais comumente utilizadas:

a) Bibliográfica: é desenvolvida a partir de material já elaborado, constituído principalmente de livros e artigos científicos. Embora em quase todos os estudos seja exigido algum tipo de trabalho desta natureza, há pesquisas desenvolvidas exclusivamente a partir de fontes bibliográficas. Parte dos estudos exploratórios podem ser definidos como pesquisas bibliográficas, assim como certo número de pesquisas desenvolvidas a partir da técnica de análise de conteúdo.

b) Documental: assemelha-se muito à pesquisa bibliográfica. A única diferença entre ambas está na natureza das fontes. Enquanto a pesquisa bibliográfica se utiliza fundamentalmente das contribuições dos diversos autores sobre determinado assunto, a pesquisa documental vale-se de materiais que não receberam ainda um tratamento analítico, ou que ainda podem ser reelaborados de acordo com os objetivos da pesquisa.

c) Experimental: o experimento representa o melhor exemplo de pesquisa científica. Essencialmente, o delineamento experimental consiste em determinar um objeto de estudo, selecionar as variáveis que seriam capazes de influenciá-lo, definir as formas de controle e de observação 
dos efeitos que a variável produz no objeto.

d) Ex-Post-Facto: investigação sistemática e empírica na qual o pesquisador não tem controle direto sobre as variáveis independentes, porque já ocorreram suas manifestações ou porque são intrinsecamente não manipuláveis. Nesse caso são feitas inferências sobre a relação entre variáveis sem observação direta, a partir da variação concomitante entre as variáveis independentes e dependentes.

e) Estudo de Coorte: refere-se a um grupo de pessoas que tem uma característica em comum, representando uma amostra não afetada. Trata-se de um estudo observacional, longitudinal, que expõe certo grupo a fatores de riscos potenciais, para em seguida ser observado, acompanhado e comparado (CAJUEIRO, 2013).

f) Levantamento de Campo (Survey): este tipo se caracterizam pela interrogação direta das pessoas cujo comportamento se deseja conhecer. Basicamente, procede-se à solicitação de informações a um grupo significativo de pessoas acerca do problema estudado para em seguida, mediante análise quantitativa, obter as conclusões correspondentes dos dados coletados.

g) Estudo de Campo: estudos de campo apresentam muitas semelhanças com os levantamentos. Distinguem-se destes, porém, em relação principalmente a dois aspectos. Primeiramente, os levantamentos procuram ser representativos de um universo definido e fornecer resultados caracterizados pela precisão estatística. Já os estudos de campo procuram muito mais o aprofundamento das questões propostas do que a distribuição das características da população segundo determinadas variáveis. Como consequência, o planejamento do estudo de campo apresenta muito maior flexibilidade, podendo ocorrer mesmo que seus objetivos sejam reformulados ao longo do processo de pesquisa. Outra distinção é a de que no estudo de campo estuda-se um único grupo ou comunidade em termos de sua estrutura social, ou seja, ressaltando a interação de seus componentes. Assim, o estudo de campo tende a utilizar muito mais técnicas de observação do que de interrogação.

h) Estudo de Caso: é caracterizado pelo estudo profundo e exaustivo de um ou de poucos objetos, de maneira a permitir o seu conhecimento amplo e detalhado, tarefa praticamente impossível mediante os outros tipos de delineamentos considerados. $\mathrm{O}$ estudo de caso é um estudo empírico que investiga um fenômeno atual dentro do seu contexto de realidade, quando as fronteiras entre o fenômeno e o contexto não são claramente definidas e no qual são utilizadas várias fontes de evidência.

\subsection{Quanto ao Tempo}

Conforme entendimento de Cajueiro (2013), tratando-se do tempo, uma pesquisa pode ser tipificada em:

a) Transversal: o pesquisador coleta os dados do experimento num único instante de tempo, obtendo um recorte momentâneo do fenômeno investigado.

b) Longitudinal: o pesquisador coleta os dados do experimento em dois ou mais momentos, havendo um acompanhamento ao longo do 
tempo do fenômeno em estudo. Nesse estudo pode-se utilizar o tempo:

1 - Retrospectivo: que estuda o acontecimento em um determinado período passado, onde se conhece o efeito e se busca a causa ou

2 - Prospectivo: que estuda desse momento em diante, por um período definido, há a causa ou fator determinante e se procura o efeito, o resultado.

\subsection{Quanto ao Local}

O local da pesquisa refere-se ao local onde será realizada a pesquisa, podendo ser, por exemplo, um laboratório, uma indústria, uma empresa, uma instituição de ensino, uma biblioteca ou um laboratório de informática.

Há a necessidade de se informar o local onde se desenvolverá a pesquisa para que se possa obter a autorização específica da pessoa responsável pelo local, anuindo com a realização do estudo, assim como é relevante esta informação para se possa ter uma ideia das condições de execução da pesquisa.

\subsection{Quanto aos Critérios de Escolha de Dados}

Nesta classificação há algumas subdivisões, para poder informar melhor quais são os dados coletados na pesquisa e como foram escolhidos.

Inicialmente, de acordo com Campana (1999), os dados podem ser:

a) Primários: correspondem a investigações originais, em que o próprio pesquisador vai obter os dados, por exemplo, realizar o experimento ou aplicar um questionário para obter os dados de que necessita.

b) Secundários: são os que procuram estabelecer conclusões a partir de estudos primários, são dados obtidos por outras pessoas e que serão utilizados para a realização do pesquisador, como por exemplo dados encontrados em artigos científicos, dados obtidos em bancos de dados públicos.

No que se trata dos critérios de escolha dos dados, Patino e Ferreira (2018) classificam em:

a) Inclusão: definidos como as características-chave da população-alvo que os investigadores utilizarão para responder à pergunta do estudo. Critérios de inclusão típicos incluem características demográficas, clínicas e geográficas, bem como idiomas dos artigos científicos utilizados em pesquisas de revisão, idade, sexo.

b) Exclusão: definidos como aspectos dos potenciais participantes que preenchem os critérios de inclusão, mas apresentam características adicionais, que poderiam interferir no sucesso do estudo ou aumentar o risco de um desfecho desfavorável para esses participantes. Critérios de exclusão comuns incluem características dos indivíduos elegíveis que fazem com que eles tenham grandes chances de perda de seguimento, de não comparecer a consultas agendadas para coletar dados, de fornecer dados imprecisos, exclusão de dados que não se enquadram nos objetivos da realização da pesquisa.

Dependendo da pesquisa, serão utilizados dados em bancos de dados, os quais podem ser:

a) Privados: são bancos de dados pertencentes a entidades, empresas privadas, como exemplo, hospitais privados, as informações, os dados não são de acesso público, neste 
caso é necessário solicitar ao responsável do local autorização para se ter acesso aos dados e caso sejam dados referentes aos seres humanos, deve-se submeter o projeto de pesquisa ao Comitê de Ética e Pesquisa.

b) Públicos: são bancos de dados que pertencem aos entes da administração pública direta e indireta, cujos dados podem ser ou não de acesso público, caso os dados estejam disponíveis publicamente, a princípio não há a necessidade de solicitar autorização do responsável pelo local para pesquisar estes dados e nem há a necessidade de submissão do projeto ao Comitê de Ética e Pesquisa, contudo se os dados não forem de livre acesso público, também se faz necessário solicitar autorização para acesso aos dados e submissão do projeto ao Comitê de Ética e Pesquisa.

Dependendo da pesquisa, principalmente ao se fazer pesquisa de revisão, há a necessidade de se estabelecer descritores, que conforme Pompei (2010) conceitua-se:

a) Descritores: são termos ou palavras-chave que a base de dados utiliza para indexar o artigo. O descritor confere maior especificidade à busca realizada em diversos banco de dados, principalmente aqueles de artigos científicos.

\subsection{Quanto ao Tratamento de Dados}

Trata-se da forma como os dados obtidos, coletados durante a realização da pesquisa serão organizados para que se possa analisar, interpretar os mesmos.

Então é importante informar se os dados serão organizados em tabelas, por exemplo, como serão estruturadas estas tabelas de forma a facilitar posterior interpretação dos dados, se serão utilizados programas de computador para organizar estes dados, quais serão estes programas e respectivas versões.

Deve-se informar se serão utilizados tratamentos estatísticos dos dados para se fazer análises, usando-se por exemplo técnica de estatística descritiva, probabilística ou inferencial.

\subsection{Quanto ao Estudo com Seres Humanos}

Quando uma pesquisa envolver seres humanos, direta ou indiretamente, deve-se observar se a pesquisa será na área de saúde ou na área de humanas, tendo em vista que se fará necessário submeter o projeto de pesquisa ao Comitê de Ética em Pesquisa respectivo.

A Resolução $\mathrm{n}^{\circ}$ 466, de 12 de dezembro de 2012 do Conselho Nacional de Saúde do Ministério da Saúde trata, dentre outras coisas, da regulamentação de condições de realização de pesquisas na área de saúde envolvendo seres humanos.

A Resolução $n^{\circ}$ 510, de 07 de abril de 2016 do Conselho Nacional de Saúde do Ministério da Saúde trata, dentre outras coisas, da regulamentação de condições de realização de pesquisas na área de humanas envolvendo seres humanos.

Então, caso haja interesse em se realizar uma pesquisa aplicando-se um questionário aos pesquisados, deve-se levar em consideração o que estabelecem estas resoluções, devendo, por exemplo verificar a não identificação dos pesquisados, aplicação do Termo de Consentimento Livre e Esclarecido - TCLE, dentre outras observações.

\section{CONCLUSÃO}

Pelo exposto pode-se concluir o quão é importante fazer uma adequada classificação da metodologia utilizada, aplicada em uma pesquisa, para facilitar sua implementação ao planejar o estudo servindo, desta forma, de 
norteamento, guia ao pesquisador, para que o mesmo consiga atingir as metas que se pretende atingir nos seus objetivos.

\section{REFERÊNCIAS}

CAJUEIRO, R. L. P. Manual para elaboração de trabalhos acadêmicos: guia prático do estudante. Rio de Janeiro: Saraiva, 2013

CAMPANA, A. O. Metodologia da investigação científica aplicada à área biomédica. Jornal de Pneumologia, São Paulo, v. 25, n. 2, p. 84-93, mar./abr., 1999

GIL, A. C. Métodos e técnicas de pesquisa social. $6^{a}$ Ed. São Paulo: Atlas, 2008

LAKATOS, E. MA; MARCONI, M. de A. Fundamentos de metodologia científica. $5^{\mathrm{a}}$ Ed. São Paulo: Atlas, 2003

MINISTÉRIO DA SAÚDE. Resolução $n^{\circ}$ 466, de 12 de dezembro de 2012 do Conselho Nacional de Saúde. 2012

MINISTÉRIO DA SAÚDE. Resolução ${ }^{\circ}$ 510, de 07 de abril de 2016 do Conselho Nacional de Saúde. 2016

OLIVEIRA, M. F. Metodologia Científica: um manual para a realização de pesquisas em administração. Catalão: UFG, 2011

PATINO, C. M.; FERREIRA, J. C. Critérios de inclusão e exclusão em estudos de pesquisa: definições e porque eles importam. Jornal Brasileiro de Pneumologia, São Paulo, v. 44, n. 2, p. 84 , mar./abr., 2018

POMPEI, L. M. Descritores ou palavraschave nas bases de dados de artigos científicos. FEMINA, Rio de Janeiro, v. 38, n. 5, p. 231-232, maio, 2010

SILVA, Cassandra Ribeiro de O.

Metodologia e organização do projeto de pesquisa: guia prático. Fortaleza: Editora da UFC, 2004 